Brit. Heart F., 1968, 30, 70.

\title{
Vectorcardiographic Evolution of Left Ventricular Hypertrophy ${ }^{\star}$
}

\author{
HUBERT BELL, DAVID PUGH, AND MARVIN DUNN
}

From the Cardiovascular Laboratory, University of Kansas Medical Center, Kansas City, Kansas, U.S.A.

Pruitt, Essex, and Burchell (1951) have suggested that the electrocardiographic manifestations of left ventricular hypertrophy are due to a conduction disturbance rather than to hypertrophy per se. Abnormal rotation of the $Q R S$ vector loop in the horizontal plane is frequently seen in patients with left ventricular hypertrophy and is attributed to incomplete left bundle-branch block, but sagittal and frontal plane rotation is usually normal. A more striking vectorcardiographic abnormality, abnormal rotation in all three planes, has been described occasionally in patients with aortic stenosis and associated left ventricular hypertrophy. Massie and Walsh (1960) cite a single case occurring in a 15-year-old boy with congenital aortic stenosis. They conclude "the explanation for the reversed direction of inscription of the QRS loop in its three planar projections is not known". Although other isolated examples of this abnormality have been reported, the frequency with which this pattern occurs is unknown. The evolution and development of this vector configuration and its accompanying pathological changes are poorly documented and understood. This study was undertaken to provide a better understanding of the relation between left ventricular hypertrophy and abnormal rotation in the three planar projections of the vector loop.

\section{SubJeCtS AND METHODS}

A Hart vectorcardiograph was used to record all tracings. The Grishman cube system utilizing a right sagittal plane was employed. A standard 12 lead electrocardiogram accompanied each vector tracing. Vectors in which abnormal rotation could be due to anterior displacement of the horizontal and sagittal loops, e.g. right ventricular hypertrophy, were excluded. Abnormal rotation was defined as clockwise in the horizontal plane and counterclockwise in the right sagittal plane. Clock-

Received January 19, 1967.

* Research supported in part by NIH Grant. wise rotation in the frontal plane was considered abnormal when the QRS axis was less than plus 35 degrees (Hugenholtz, Whipple, and Levine, 1961; Scherlis, Lasser, and Grishman, 1951). If the efferent limb rotated abnormally, the loop was considered to have abnormal rotation even if the afferent limb produced a figure-of-eight configuration. In all, 2800 vectorcardiograms were reviewed, of which approximately 300 were from patients with aortic valvular disease.

The clinical history was reviewed in the 34 cases demonstrating abnormal rotation. Cardiac catheterization data as well as surgical and necropsy findings were noted. Established electrocardiographic criteria were used for the diagnosis of myocardial infarction and left ventricular hypertrophy (Massie and Walsh, 1960). A compatible clinical history was used as confirmatory evidence of myocardial infarction when an evolving pattern of infarction was not present. Confirmation of infarction was present at necropsy in 3 cases. $X$-ray demonstration of left ventricular enlargement was used as confirmatory evidence of left ventricular hypertrophy. Confirmation of hypertrophy was present at necropsy in 6 cases. The diagnosis of aortic valvular disease was made on the basis of typical physical findings in all cases and was confirmed by left heart catheterization ( 15 cases) or operation (9 cases). Confirmation of aortic valvular disease was present at necropsy in 5 cases. Gorlin's formula (Gorlin and Gorlin, 1951) was used to calculate the aortic valve area from catheterization data, and aortic insufficiency was assessed by sampling indocyanine green dye at the level of the left subclavian artery following injection at various levels in the descending aorta.

\section{RESULTS}

Of the 2800 vectorcardiograms reviewed, 23 were selected on the basis of abnormal vector loop rotation in all three planes, incomplete left bundlebranch block, and voltage criteria for left ventricular hypertrophy. All 23 tracings were from patients with severe aortic valvular disease who had no evidence of associated myocardial infarction. These 23 patients represent 8 per cent of 300 patients with aortic disease who were studied. 
TABLE I

HAEMODYNAMIC AND VECTORCARDIOGRAPHIC FINDINGS IN 23 PATIENTS WITH AORTIC VALVE DISEASE, ALL WITH LEFT VENTRICULAR HYPERTROPHY

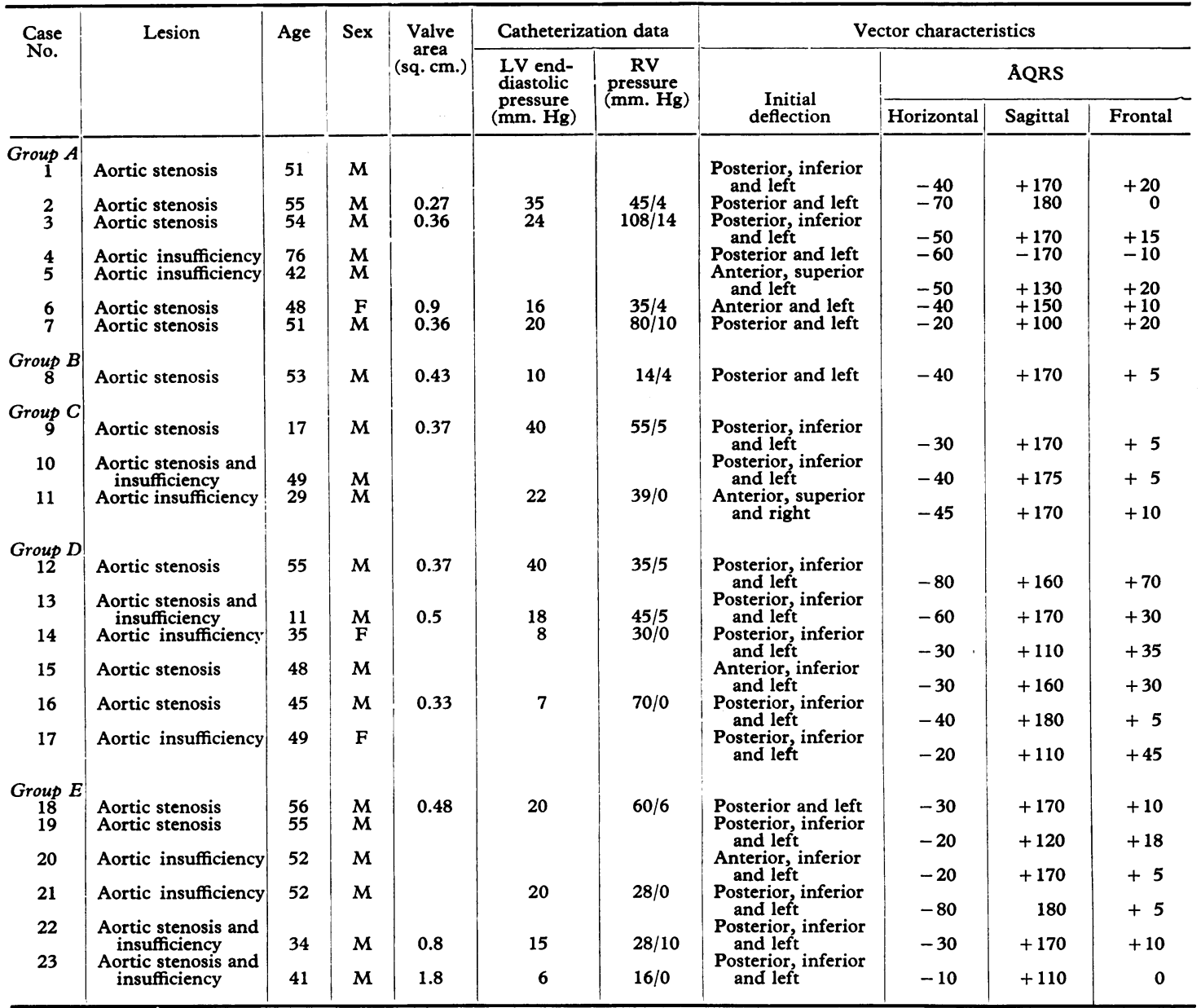

The patients were divided into five groups on the basis of their vector loop configuration (Table I, Fig. 1). Group A had completely abnormal rotation in all three planes (Fig. 2 and 3). Group B was slightly less abnormal, with a figure-of-eight in the horizontal plane but completely abnormal rotation in the frontal and sagittal planes. Group C (Fig. 4 and 5) had abnormal rotation in the horizontal and sagittal planes and abnormal efferent limb rotation in the frontal plane. Group D (Fig. 6 and 7) had relatively normal (counterclockwise) rotation in the frontal plane except for a small figure-of-eight in the midportion of the loop, but there was completely abnormal rotation in the horizontal and sagittal planes. Group E was the most nearly normal, with figure-of-eight configurations in all three planes with only the efferent limbs of the loops rotating abnormally. No correlation existed between severity of aortic valve disease, left ventricular end-diastolic pressure, right ventricular pressure, and the vectorcardiographic abnormality. The vector loops became more abnormal in four patients (Cases 3, 5,10 , and 13) as their aortic valvular disease became more severe (Fig. 6 and 7). The vector loops lost their abnormal configurations partially or completely in five patients (Cases 2, 8, 9, 12, and 18) following aortic valve surgery (Fig. 2, 3, 4, and 5). The changing configuration of the vector loops suggests that the arbitrary groups represent stages in the development of left ventricular hypertrophy in individual patients, but not in the group as a whole. 


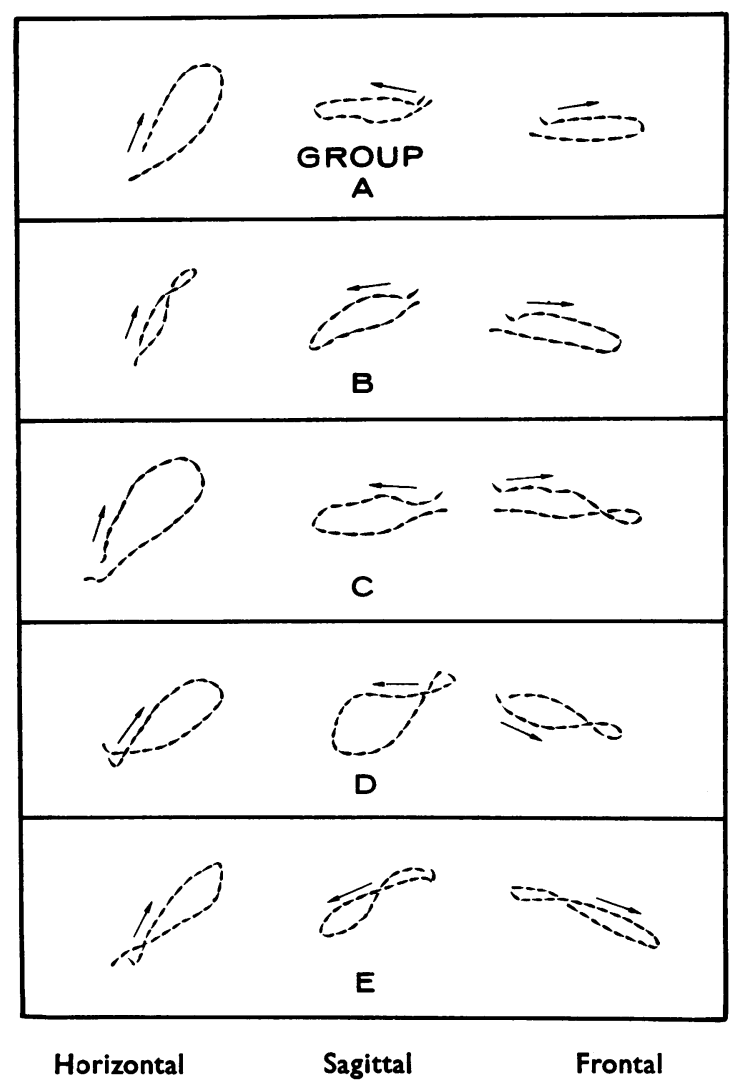

FIG. 1.-The typical vectorcardiographic appearance of the five aortic groups is illustrated. Group $A$ is the most abnormal with completely abnormal rotation in all three planes. The other groups demonstrate variations of this configuration. The arrows indicate direction of rotation.

Eleven additional patients with abnormal vector loop rotation due to myocardial infarction are listed in Table II. The marked superior displacement of the efferent limbs met the criteria of Hugenholtz et al. (1961) for inferior infarction (Fig. 8 and 9). One patient (Case 31 ) had only a moderate amount of superior displacement of the efferent limbs and presented a vector appearance that was intermediate between the aortic and infarction groups. At necropsy both moderately severe aortic stenosis and a small apical infarction were found.

Necropsy findings are summarized in Table III. Confirmation of left ventricular hypertrophy and aortic stenosis without myocardial infarction was present at necropsy in 5 cases. All the patients with aortic disease had marked left ventricular hypertrophy with heart weights over $600 \mathrm{~g}$. Diffuse

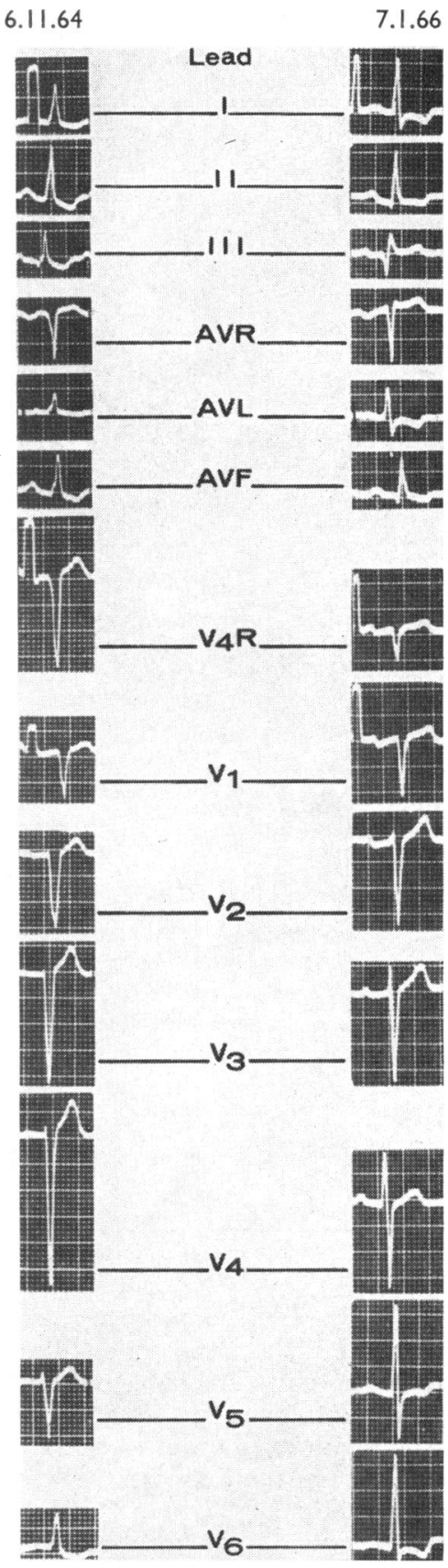

Fig. 2-Electrocardiographic changes occurring after operation to correct severe aortic stenosis (Case 2). In the initial electrocardiogram there is evidence of left ventricular hypertrophy and incomplete left bundle-branch block.

myocardial fibrosis on microscopical section was seen in all patients with aortic valve disease, including the patient who had both aortic stenosis and a small 


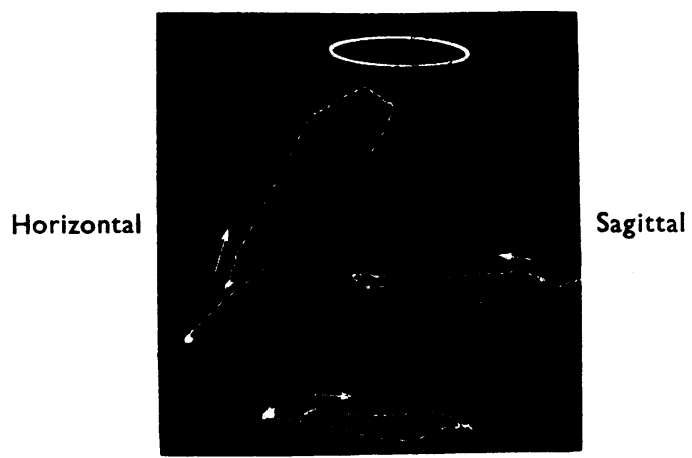

Frontal 16.11 .64

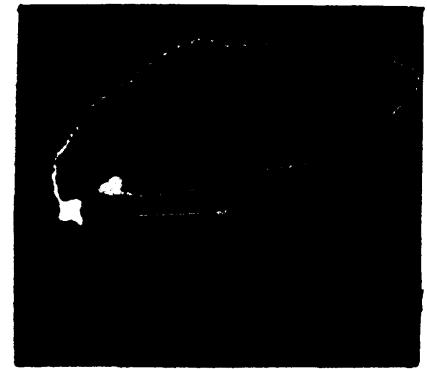

Horizontal

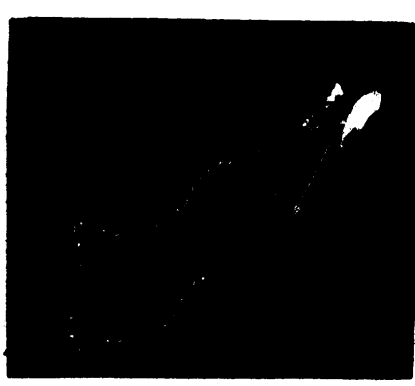

Sagittal

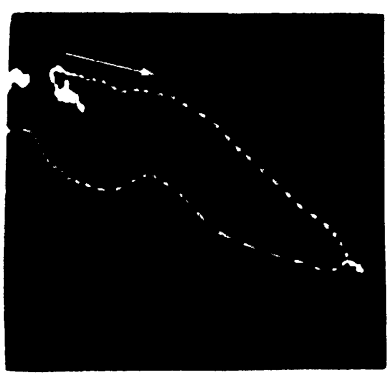

8.1 .66

Fig. 3.-Changes in the vectorcardiogram (Case 2). The initial vector tracing demonstrates abnormal rotation in all 3 planes (Group A), and absent septal forces. Following insertion of a Starr-Edwards prosthetic valve, the vectorcardiogram developed normal rotation of the horizontal and sagittal loops and a septal vector appeared.

infarction in the apical portion of the interventricular septum. The other two patients who had necropsies had extensive infarctions that involved the apex of the left ventricle.

\section{Discussion}

In 4 patients, the gradual development of abnormal rotation was demonstrated on serial vector- cardiograms as their aortic disease became more severe. In these patients, the configuration of the vector loops evolved through 5 stages of development that correlated with the haemodynamic severity of the aortic lesion. The scalar tracings demonstrated evidence of left ventricular hypertrophy of increasing severity on the basis of increased QRS voltage and $T$ wave inversion. Case 10 evolved from figure-of-

TABLE II

VECTORCARDIOGRAPHIC FINDINGS IN MYOCARDIAL INFARCTION

\begin{tabular}{|c|c|c|c|c|c|c|c|}
\hline \multirow{3}{*}{$\begin{array}{l}\text { Case } \\
\text { No. }\end{array}$} & \multirow[t]{3}{*}{ Age } & \multirow[t]{3}{*}{ Sex } & \multirow{3}{*}{$\begin{array}{c}\text { Left } \\
\text { ventricular } \\
\text { hypertrophy }\end{array}$} & \multicolumn{4}{|c|}{ Vector characteristics } \\
\hline & & & & \multirow{2}{*}{$\begin{array}{c}\text { Initial } \\
\text { deflection }\end{array}$} & \multicolumn{3}{|c|}{ ÅQRS } \\
\hline & & & & & Horizontal & Sagittal & Frontal \\
\hline $\begin{array}{l}24 \\
25 \\
26 \\
27 \\
28 \\
29 \\
30 \\
31 \\
32 \\
33 \star \\
34\end{array}$ & $\begin{array}{l}74 \\
77 \\
71 \\
45 \\
47 \\
75 \\
67 \\
61 \\
62 \\
56 \\
73\end{array}$ & $\begin{array}{l}\mathbf{F} \\
\mathbf{F} \\
\mathbf{M} \\
\mathbf{M} \\
\mathbf{M} \\
\mathbf{M} \\
\mathbf{M} \\
\mathbf{M} \\
\mathbf{M} \\
\mathbf{M} \\
\mathbf{F}\end{array}$ & $\begin{array}{l}\text { Yes } \\
\text { Yes } \\
\text { No } \\
\text { No } \\
\text { No } \\
\text { No } \\
\text { No } \\
\text { No } \\
\text { No } \\
\text { Yes } \\
\text { No }\end{array}$ & $\begin{array}{l}\text { Posterior, superior and right } \\
\text { Posterior, superior and right } \\
\text { Posterior, superior and right } \\
\text { Posterior, superior and right } \\
\text { Posterior, superior and right } \\
\text { Posterior and superior } \\
\text { Posterior, superior and right } \\
\text { Posterior, superior and right } \\
\text { Posterior, superior and left } \\
\text { Posterior and superior } \\
\text { Posterior, superior and right }\end{array}$ & $\begin{array}{l}-30 \\
-30 \\
-50 \\
-20 \\
-70 \\
-60 \\
-80 \\
-10 \\
-60 \\
-30 \\
-60\end{array}$ & $\begin{array}{r}+170 \\
+110 \\
180 \\
180 \\
+170 \\
180 \\
-170 \\
+90 \\
+130 \\
+170 \\
-170\end{array}$ & $\begin{array}{r}0 \\
+35 \\
0 \\
0 \\
+\quad 5 \\
0 \\
+20 \\
0 \\
+35 \\
+35 \\
-20\end{array}$ \\
\hline
\end{tabular}

^Patient also had aortic stenosis. 


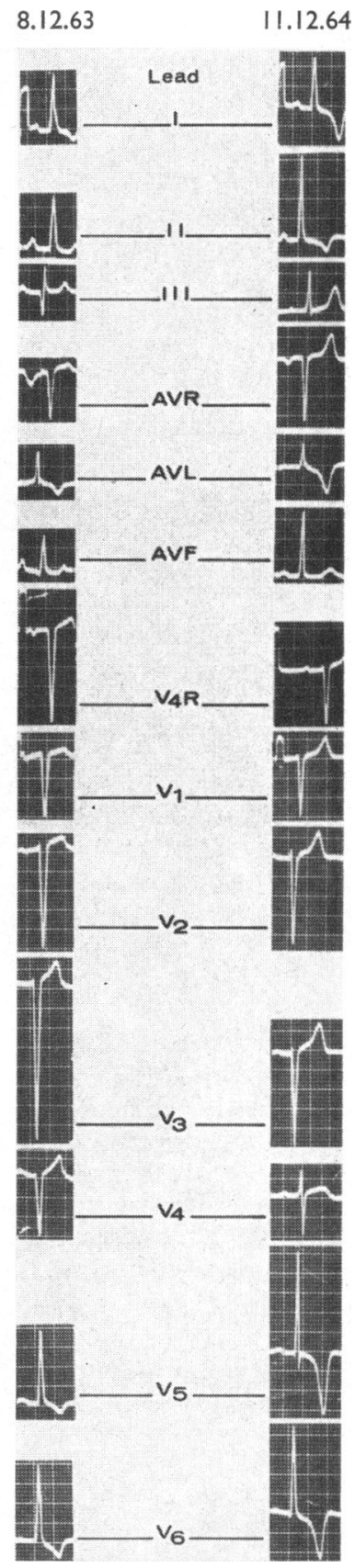

FIG. 4.-Electrocardiographic changes after aortic valve operation in a 17-year-old boy with congenital aortic stenosis (Case 9).

eight with abnormal efferent limb rotation in all planes to completely abnormal horizontal and sagittal plane rotation with abnormal frontal efferent limb rotation (Group E to Group C) within 12 months.
TABLE III

FINDINGS AT NECROPSY

\begin{tabular}{|c|c|c|c|c|}
\hline $\begin{array}{l}\text { Case } \\
\text { No. }\end{array}$ & Group & $\begin{array}{c}\text { Heart } \\
\text { weight } \\
\text { (g.) }\end{array}$ & $\begin{array}{c}\text { Aortic } \\
\text { valve } \\
\text { (sq. cm.) }\end{array}$ & Infarction \\
\hline $\begin{array}{r}1 \\
8 \\
13 \\
15 \\
19 \\
33 \\
26 \\
32\end{array}$ & $\begin{array}{c}\text { A } \\
\mathbf{B} \\
\mathbf{D} \\
\mathbf{D} \\
\mathbf{E} \\
\text { Infarctiont } \\
\text { Infarction } \\
\text { Infarction }\end{array}$ & $\begin{array}{l}840 \\
640 \\
650 \\
910 \\
840 \\
690 \\
350 \\
400\end{array}$ & $\begin{array}{c}0.5 \\
\text { n/a } \\
0.5 \\
0.5 \\
1.0 \\
1.5 \\
\text { Normal } \\
\text { Slight narrowing }\end{array}$ & $\begin{array}{l}\text { No } \\
\text { No } \\
\text { No } \\
\text { No } \\
\text { No } \\
\text { Yes } \\
\text { Yes } \\
\text { Yes }\end{array}$ \\
\hline
\end{tabular}

*Patient died immediately after aortic valve replacement. †Patient had both aortic stenosis and infarction.

Case 13 evolved from normal to Group D within 30 months (Fig. 6 and 7). Case 3 changed from normal to completely abnormal rotation in all three planes (Group A) within 36 months, evolving through Group C, as the aortic stenosis became more severe. Case 5 also changed from Group $C$ to Group $A$ as the aortic insufficiency became more severe. In 5 patients (Cases 2, 8, 9, 12, and 18), there was a rapid return of normal vector loop rotation in all 3 planes following corrective aortic valve operation (Fig. 2 and 3). The scalar tracings also showed a rapid return toward normal with loss of evidence of left ventricular hypertrophy. In Case 9 (Fig. 4 and 5), a 17-year-old boy with congenital aortic stenosis and insufficiency, the abnormal rotation disappeared within 7 months of operation; and in Case 16, the vector returned to normal within 2 weeks of operation.

The mechanism of production of abnormal vector loop rotation in patients with aortic valvular disease is unknown. Although incomplete left bundlebranch block was present in the tracings, this condition alone could not explain the completely abnormal rotation in the horizontal plane, because incomplete left bundle-branch block causes only a figure-of-eight configuration in this plane (Luna and Jackson, 1961; Scherlis and Grishman, 1951; Sanchez, Walsh, and Massie, 1961). Complete left bundle-branch block could explain the clockwise rotation in the horizontal plane, but the total QRS duration is not sufficiently prolonged for this diagnosis (Scherlis and Grishman, 1951). Complete left bundle-branch block alone could not account for abnormal rotation in the frontal and sagittal planes (Luna and Jackson, 1961; Scherlis and Grishman, 1951; Sanchez et al., 1961). Massie and Walsh (1960) have described completely abnormal rotation in all planes occurring in a 15-year-old boy with congenital aortic stenosis. They feel this is due to left ventricular hypertrophy. Dickens, Maranhao, and Goldberg (1959) have described one patient with 

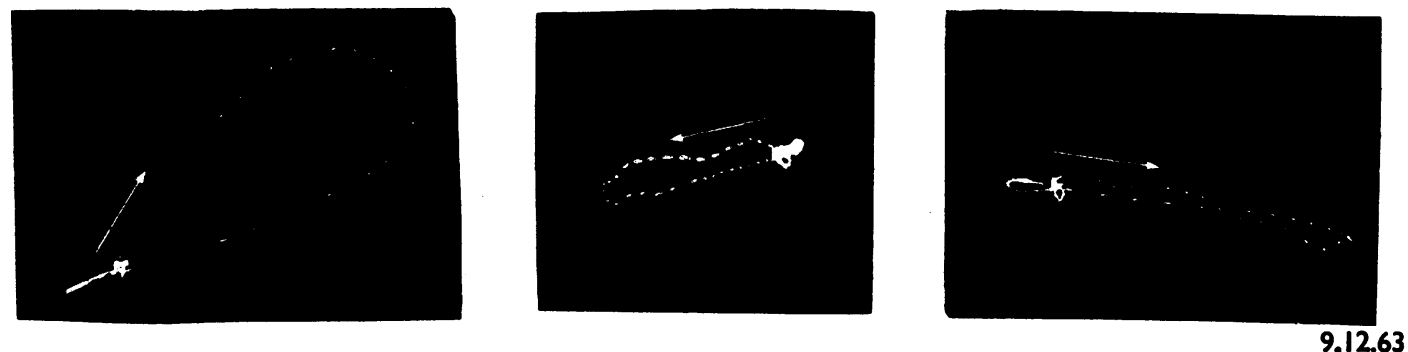

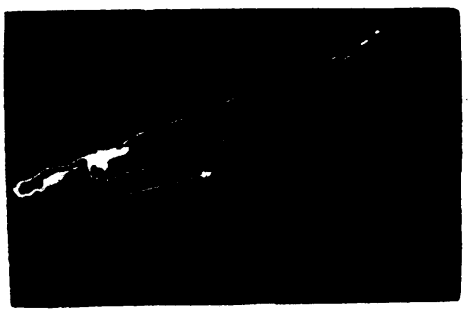

Horizontal

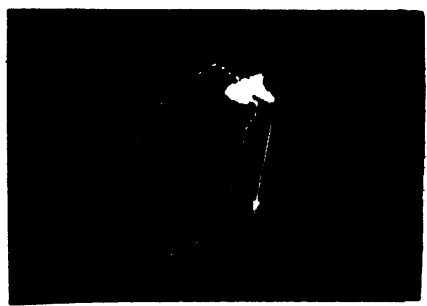

Sagittal

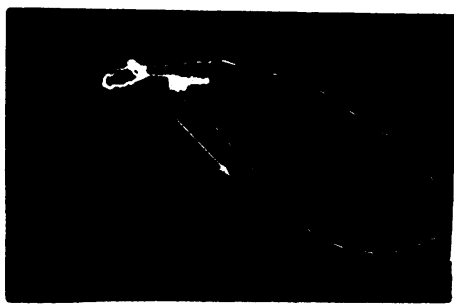

Frontal abnormal rotation in all planes among their 31 patients with left ventricular hypertrophy and incomplete left bundle-branch block. Their patient also had severe aortic valvular disease. Mazzoleni, Wolff, and Wolff (1959), in their discussion of 100 patients with left ventricular hypertrophy, reported abnormal sagittal plane rotation in 5 who had no evidence of infarction; however, an accompanying clinical diagnosis was not given in these patients. Patients with calcific aortic stenosis sometimes have diffuse patchy areas of fibrosis or necrosis without coronary artery disease. It is possible that a combination of left ventricular hypertrophy and myocardial fibrosis could produce the abnormal depolarization that is responsible for their unusual vector configuration.

There was no correlation between the left ventricular end-diastolic pressure rise and abnormal vectorcardiographic findings in the group as a whole. This excludes heart failure per se as the cause for the abnormal vectorcardiographic rotation. Similarly, there was no correlation between right ventricular pressure and abnormal frontal and sagittal plane rotation, which excludes associated right ventricular hypertrophy as the cause for the vectorcardiographic abnormality.
The rapid reversibility of the abnormal configuration excludes focal fibrosis as the only explanation for the conduction disturbance. The evolution of the abnormal vectorcardiographic configuration as the disease becomes more severe and its rapid regression after corrective aortic valve surgery suggest that these changes are not due to hypertrophy per se. These changes are probably due to conduction defects secondary to hypertrophy or disturbed haemodynamics. This is evidently an individual variation since it was seen in only 8 per cent of patients with aortic valve disease and does not correlate with the usual parameters expressing severity of aortic valve disease.

The presence of abnormal rotation in all planes in patients with aortic valvular disease and left ventricular hypertrophy could be misinterpreted to indicate extensive infarction. Both antero-septal and antero-lateral infarction can cause abnormal clockwise rotation in the horizontal plane (Hugenholtz et al., 1961). Abnormal sagittal and frontal plane rotation occur with apical infarction (Hugenholtz et al., 1961). These authors have stated that the detection of abnormal rotation in the frontal and sagittal planes should be considered the most important criterion for the diagnosis of apical infarc- 


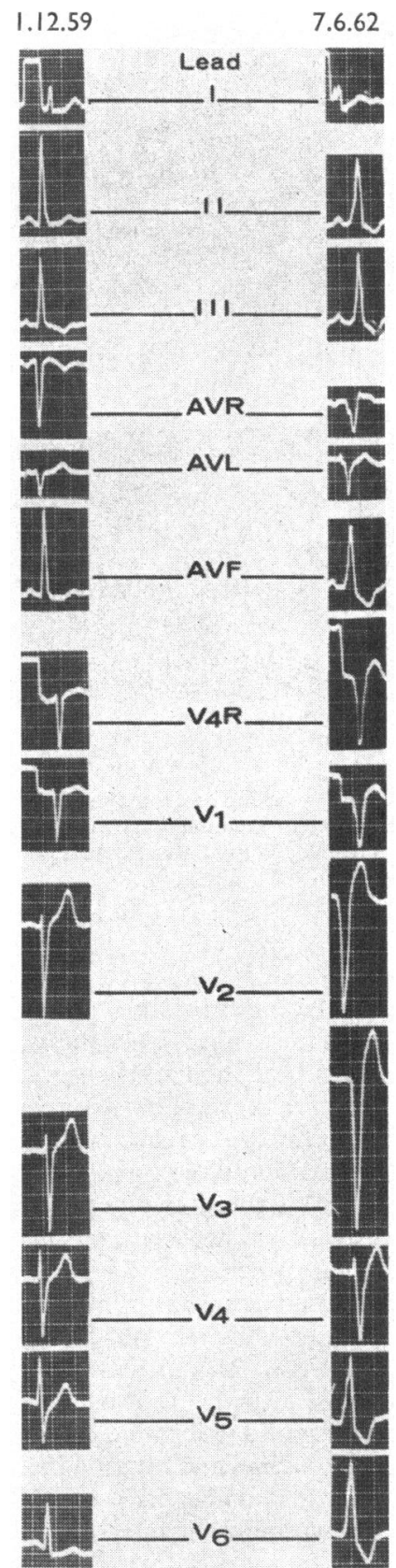

Fig. 6.-Electrocardiogram from an 11-year-old boy with congenital aortic stenosis (Case 13). As the aortic stenosis became clinically more severe, the electrocardiogram demonstrated an incomplete left bundle-branch block and increased left ventricular hypertrophy.

tion. While a figure-of-eight configuration in the frontal plane is not uncommon in normal individuals when the maximum QRS axis is between plus 15 and plus 75 degrees, counterclockwise rotation is the rule when the axis is less than 18 degrees (Scherlis et al., 1951). In every tracing in our aortic Groups $\mathrm{C}$ and $\mathrm{E}$, figure-of-eight configuration occurred in frontal plane when the axis was less than 18 degrees and could, therefore, be considered abnormal. In these groups, the figure-of-eight was usually produced by the terminal part of the afferent limb crossing over an abnormal clockwise efferent limb. All patients in Group D had completely abnormal, counterclockwise rotation in the sagittal plane. Hugenholtz et al. (1961) stated that abnormal rotation of the sagittal plane, even in the absence of prolonged superior forces, suggested apical infarction. It is important to note that aortic stenosis can cause abnormal rotation in the absence of infarction so these rotational abnormalities will not be inferred to reflect associated infarction.

The vector loops of the patients with aortic valvular disease and left ventricular hypertrophy showed striking differences from the vector loops of patients with extensive infarction. Left ventricular hypertrophy was present in all of the aortic group and in only three of the infarction group. Eight of the patients with infarction had an initial deflection in the horizontal plane that was directed to the right and posteriorly, thereby suggesting antero-lateral infarction. None of the patients with aortic disease had an initial deflection that was directed to the right and posteriorly. Four of the aortic group had an initial deflection that was directed anteriorly and to the left, resembling left bundle-branch block, while none of the infarction patients had such a pattern. The most striking difference in the two groups was seen in the sagittal and frontal planes, where a marked superior displacement of the initial part of the efferent limb was present in all of the infarction group but in none of the aortic group. Only two patients with aortic disease (Cases 5 and 9) had an initial superior deflection, but this was not of sufficient duration for diagnosis of an inferior infarction. Both patients had severe aortic insufficiency and the superior initial deflection probably represented septal hypertrophy. The vectorcardiogram of the patient who had both aortic stenosis and apical infarction had only a slight amount of superior displacement, and the configuration in all loops more closely resembled the aortic group than the infarction group.

It is possible that other conditions causing marked left ventricular hypertrophy, e.g. systemic hypertension, coarctation of the aorta, and subvalvular aortic stenosis, could also result in abnormal vector loop rotation in all three planes. Patients with aortic valve disease were studied because of their preponderance in the patient material we encounter. 

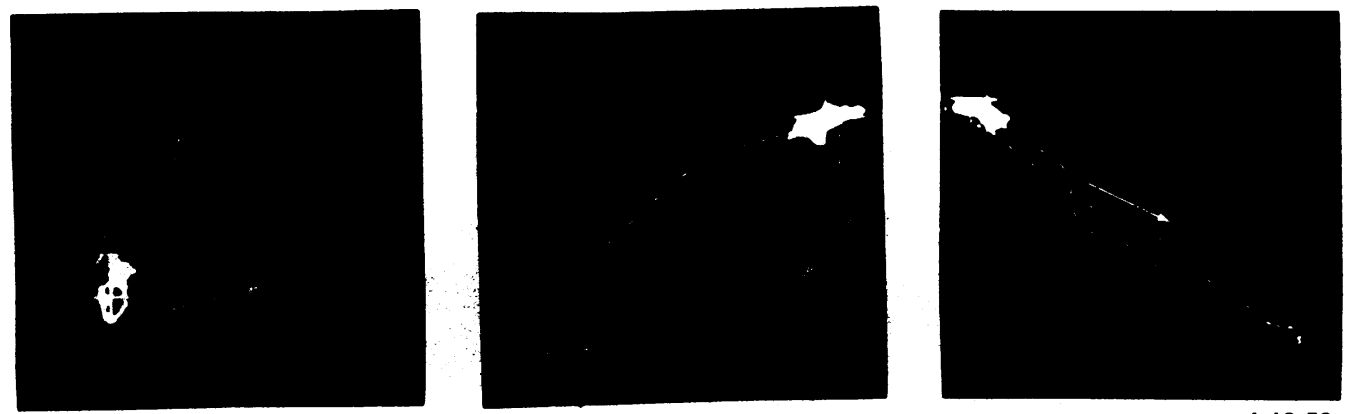

1.12 .59

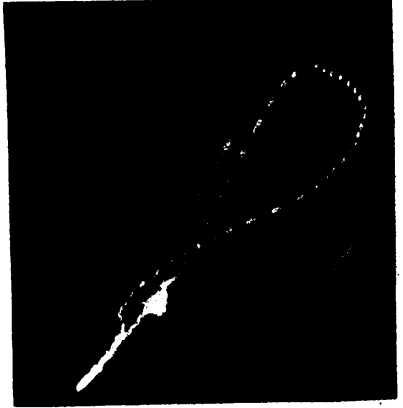

Horizontal

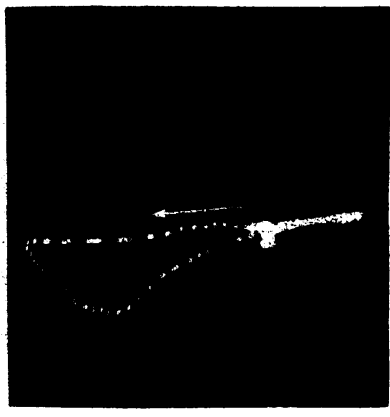

Sagittal

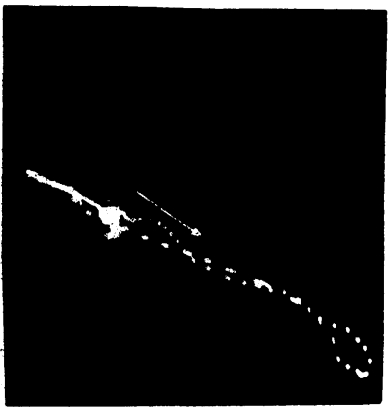

Frontal
In addition, a study of patients with aortic valve disease allowed us to follow the regression of the vector abnormality when normal haemodynamics returned after aortic valve replacement.

Pruitt et al. (1951) reported an experiment performed on the isolated, perfused canine heart preparation in which a 5 per cent cocaine solution was infused into the left ventricle. As the cocaine solution was infused, QRS complexes appeared that showed the development of incomplete left bundlebranch block. The complexes gradually developed a tall $R$ wave, depressed S-T segments, and inverted $T$ waves which resembled left ventricular hypertrophy with "strain." Pruitt concluded that the origin of the electrocardiographic signs of left ventricular hypertrophy might lie in a conduction disturbance as distinguished from an increase in thickness of the ventricular wall. In these patients with aortic valve disease and abnormal rotation of QRS loop the evidence of left ventricular hypertrophy appeared as the conduction disturbance became more severe and tended to disappear as the conduction disturbance disappeared. The rapidity of these changes lends credence to Pruitt's theory and suggests that both the abnormal direction of depolarization and some of the evidence of left ventricular hypertrophy are due to conduction disturbance.

\section{SUMMARY}

In a review of 2800 vectorcardiograms, 23 were found to have abnormal vector loop rotation in all three planes associated with evidence of incomplete left bundle-branch block and left ventricular hypertrophy. All 23 tracings were from patients with severe aortic valvular disease who had no evidence of associated myocardial infarction. This represents only 8 per cent of 300 patients with aortic disease who were studied. In 4 patients the gradual development of abnormal rotation in all 3 vector planes was demonstrated on serial vectorcardiograms as their aortic disease became more severe. The configuration of the vector loops evolved through 5 stages of development that correlated with the haemodynamic severity of the aortic lesion in these individual cases, but there was no correlation in the group as a whole between the vectorcardiographic changes and the usual parameters expressing severity of aortic disease. In 5 patients there was a rapid return to normal vector loop rotation in all 3 planes 
FIG. 8.-The electrocardiogram from a 73-year-old woman with clinical evidence of extensive myocardial infarction (Case 34) demonstrates anterior and inferior infarction.

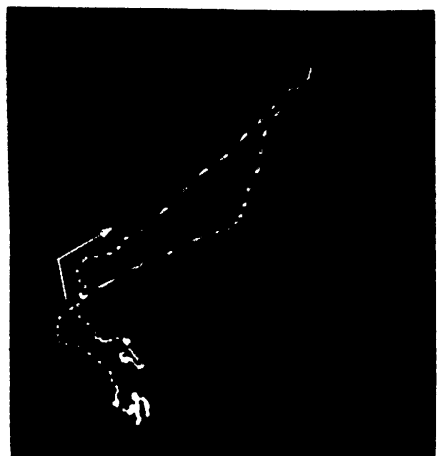

Horizontal

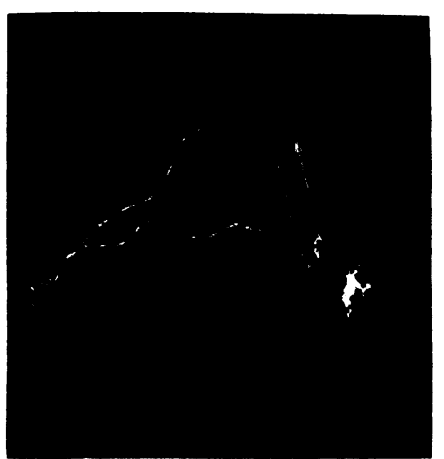

Sagittal

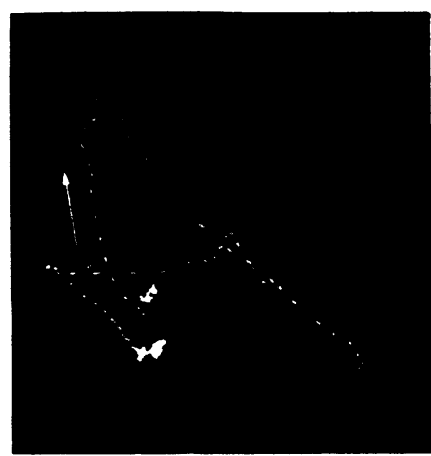

Frontal

FIG. 9.-The vectorcardiogram demonstrates abnormal rotation in all three planes (Case 34). The initial deflection in the horizontal plane is posterior and to the right, and there is a marked superior initial deflection in the sagittal and frontal planes. 
following corrective aortic valve operation. The scalar tracings also showed a rapid return toward normal. The rapidity of these changes suggests that both the abnormal direction of depolarization and some of the evidence of left ventricular hypertrophy were due to conduction disturbance.

\section{REFERENCES}

Dickens, J., Maranhao, V., and Goldberg, H. (1959). Ventricular endocardial leads in left bundle branch block and left ventricular hypertrophy. Amer. F. Cardiol., 3, 472.

Gorlin, R., and Gorlin, S. G. (1951). Hydraulic formula for calculation of the area of the stenotic mitral valve, other cardiac valves, and central circulatory shunts. Amer. Heart f., 41, 1.
Hugenholtz, P. G., Whipple, G. H., and Levine, H. D. (1961). A clinical appraisal of the vectorcardiogram in myocardial infarction. I. The cube system. Circulation, 24, 808.

Luna, R., and Jackson, A. (1961). The vectorcardiogram in left bundle-branch block. Amer. F. Cardiol., 7, 638.

Massie, E., and Walsh, T. J. (1960). Clinical Vectorcardiography and Electrocardiography. Year Book Publishers, Chicago.

Mazzoleni, A., Wolff, R., and Wolff, L. (1959). The vectorcardiogram in left ventricular hypertrophy. Amer. Heart $\mathcal{F} ., 58,648$.

Pruitt, R., Essex, H. E., and Burchell, H. B. (1951). Studies on the spread of excitation through the ventricular myocardium. Circulation, 3, 418.

Sanchez, C., Walsh, T. J., and Massie, E. (1961). The vectorcardiogram in incomplete left bundle-branch block. Amer. F. Cardiol., 7, 629.

Scherlis, L., and Grishman, A. (1951). Spatial vectorcardiography: left bundle-branch block and left ventricular hypertrophy. Amer. Heart f., 41, 494.

- Lasser, R. P., and Grishman, A. (1951). Spatial vectorcardiography: The normal vectorcardiogram, VI. Amer. Heart f., 42, 235. 